\title{
Karakteristik Laser Retinopexy pada Pasiendengan Tear Retina di Divisi Vitreoretina RS Cipto Mangunkusomo Periode Januari - Desember 2018
}

\author{
Ashan, $\mathrm{H}^{1}$ \\ ${ }^{1}$ Departemen Ilmu Kesehatan Mata \\ Fakultas Kedokteran Universitas Indonesia/ Rumah Sakit Cipto Mangunkusumo Jakarta, Indonesia \\ E-mail : havesashan@gmail.com
}

\begin{abstract}
Abstrak
Retinal detachment merupakan suatu kondisi serius yang mengancam penglihatan sehingga dapat menimbulkan komplikasi kebutaan. Satu - satunya tatalaksana untuk retinal detachment tersebut adalah tindakan bedah, dimana tidak seluruh tindakan bedah pada kasus retinal detachment memiliki tingkat keberhasilan yang baik. Oleh karena itu, sangat penting untuk dapat menemukan tear pada retina, sebelum berkembang lebih lanjut menjadi detachment. Laser retinopexy yang dilakukan dengan tujuan menimbulkan efek adhesi disekililing tear pada retina, telah direkomendasikan sebagai sebuah tindakan untuk mencegah terjadinya komplikasi retinal detachment. Laser retinopexy mempunyai peranan penting pada pasien dengan retinal tear yang memiliki simptom floaters dan flashing serta traksi yang persisten pada retina terutama pada area sekitar retinal tear, karena symptomatic retinal tear berkemungkinan besar untuk berkembang menjadi komplikasi retinal detachment. Namun, walaupun laser retinopexy sering direkomendasikan, pada kenyataanya, efektivitas tindakan ini masih kontroversial.
\end{abstract}

Katakunci — Retinal detachment, laser retinopexy, retinal tear

\begin{abstract}
Retinal detachment is a serious condition that threatens vision so that it can cause complications of blindness. The only treatment for retinal detachment is surgery, where not all surgical procedures in retinal detachment cases have a good success rate. Therefore, it is very important to be able to find tears in the retina, before developing further into detachments. Retinopexy lasers performed with the aim of causing adhesion around the tear in the retina, have been recommended as an action to prevent complications of retinal detachment. Retinopexy laser has an important role in patients with retinal tear who have symptoms of floaters and flashing and persistent traction in the retina especially in the area around the retinal tear, because symptomatic retinal tear is likely to develop into a complication of retinal detachment. However, although laser retinopexy is often recommended, in fact, the effectiveness of this action is still controversial.
\end{abstract}

Keywords - Retinal detachment, laser retinopexy, retinal tear 


\section{Pendahuluan}

Retinal detachment merupakan suatu kondisi serius yang mengancam penglihatan sehingga dapat menimbulkan komplikasi kebutaan. Satu - satunya tatalaksana untuk retinal detachment tersebut adalah tindakan bedah, dimana tidak seluruh tindakan bedah pada kasus retinal detachment memiliki tingkat keberhasilan yang baik. Oleh karena itu, sangat penting untuk dapat menemukan tear pada retina, sebelum berkembang lebih lanjut menjadi detachment. ${ }^{1-7}$

Penyebab utama terjadinya tear pada retina adalah Posterior Vitreous Detachment (PVD). PVD sangat sering dijumpai dan mempunyai kaitan erat dengan usia pasien. PVD merupakan kondisi dimana terpisahnya vitreous cortex dengan internal limiting membrane karena adanya proses likuifaksi ( pengenceran ) pada vitreus itu sendiri. Walaupun secara umum PVD tersebut tidak berbahaya, tetapi dapat menjadi kondisi yang serius pada tractional retinal tears dan retinal detachment.

Gejala paling sering dikeluhkan pasien dengan PVD adalah adanya floaters dan flashing. Gejala floaters dan flashing ini umum ditemukan pada pasien dengan usia diatas 45 tahun. Oleh karena adanya kemungkinan komplikasi yang dapat ditimbulkan oleh PVD tersebut, sanagat penting untuk mengetahui adanya gejala floaters dan flashing pada pasien untuk mencegah terjadinya tear yang dapat berlanjut menjadi retinal detachment. ${ }^{1-7}$

Retinal tear merupakan sebuah lesi yang menjadi faktor resiko terjadinya retinal detachment. Retinal detachment terjadi bila proses likuifaksi masuk melaui tear dan memisahkan retina dengan lapisan dibawahnya yaitu retinal pigmen epithelium. Laser retinopexy yang dilakukan dengan tujuan menimbulkan efek adhesi disekililing tear pada retina, telah direkomendasikan sebagai sebuah tindakan untuk mencegah terjadinya komplikasi retinal detachment. Laser retinopexy mempunyai peranan penting pada pasien dengan retinal tear yang memiliki simptom floaters dan flashing serta traksi yang persisten pada retina terutama pada area sekitar retinal tear, karena symptomatic retinal tear berkemungkinan besar untuk berkembang menjadi komplikasi retinal detachment. Namun, walaupun laser retinopexy sering direkomendasikan, pada kenyataanya, efektivitas tindakan ini masih kontroversial. $^{8-9}$

\section{Metodologi Penelitian}

Desain penelitian adalah deskriptif retrospektif berdasarkan hasil penelusuran rekam medis. Tempat penelitian yaitu di Divisi Vitreoretina, Departemen Ilmu Kesehatan Mata FKUI-RSCM Kirana, Jakarta. Waktu dan sampel penelitian diambil dari rekam medis periode Januari sampai Desember 2018. Populasi terjangkau adalah pasien dengan tear retina di divisi vitreoretina yang menjalani tindakan laser retinopexy di Departemen Ilmu Kesehatan Mata RSCM Kirana, periode Januari - Desember 2018.

Kriteria inklusi adalah seluruh data pasien dengan tear retina yang menjalani tindakan laser retinopexy. Kriteria eksklusi adalah data pasien yang tidak lengkap, data pasien yang tidak kontrol serta rekam medis yang tidak dapat ditelusuri.

\section{HASIL}

Berdasarkan penelusuran data rekam medis didapatkan 17 pasien dengan tear retina yang menjalani tindakan laser retinopexy di ruang tindakan laser Rumah Sakit Cipto Mangunkusumo Kirana periode Januari hingga Desember 2018. Sebanyak 3 subjek dieksklusi karena pasien tidak kontrol ulang, maupun rekam medis yang tidak dapat ditelusuri. Jumlah data rekam medis yang dapat diolah menjadi sampel penelitian

Email : heme@unbrah.ac.id 
sebanyak 14 subjek.

Karakteristik umum subjek penelitian, dari 14 subjek, sebanyak 9 orang $(64,3 \%)$ berjenis kelamin pria dan 5 orang $(35,7 \%)$ berjenis kelamin wanita. Mayoritas pasien memiliki rentang usia 41-50 tahun $(42,8 \%)$ dan 31-40 tahun (28,6\%), rentang usia 51-60 tahun $(28,6 \%)$. Asal rujukan yaitu dari Jabodetabek sebesar $92,9 \%$ dan luar Jabodetabek sebesar 7,1\%.

Karakteristik klinis subjek penelitian terlihat lateralitas terbanyak didapatkan pada mata kiri yaitu 10 orang $(71,4 \%)$ sedangkan mata kanan 4 orang $(28,6 \%)$.

Visus awal saat datang mayoritas antara $\geq$ $6 / 18$ yaitu sebanyak 11 orang $(78,6 \%)$, visus $<6 / 18-6 / 60$ sebanyak 2 orang $(14,3 \%)$, visus $<1 / 60$ - LP sebanyak 1 orang $(7,1 \%)$. Dua minggu pasca laser retinopexy didapatkan visus $\geq 6 / 18$ yaitu sebanyak 11 orang $(78,6 \%)$, visus $<6 / 18-6 / 60$ sebanyak 2 orang $(14,3 \%)$, visus $<1 / 60-$ LP sebanyak 1 orang $(7,1 \%)$. Satu pasien mengalami penurunan visus dari $0,5 / 60$ menjadi $1 / 300$.

Lokasi tear retina mayoritas ditemukan di Superotemporal sebanyak 7 orang $(50,0 \%)$, kemudian Inferotemporal sebanyak 6 orang $(42,9 \%)$, dan Superonasal sebanyak 1 orang $(7,1 \%)$. Satu pasien mengalami komplikasi setelah 2 minggu tindakan laser retinopexy, dimana tear retina berkembang menjadi Rhegmatogen Retinal Detachment.

\section{Pembahasan}

Rhegmatogenous retinal detachment merupakan suatu kondisi sight treating yang relatif sering dijumpai. Ketika detachment telah terjadi, tindakan yang dapat dilakukan hanyalah melalui tindakan bedah yang relatif sulit yang hanya dapat dilakukan oleh vitreoretinal surgeon. Langkah awal yang dapat dilakukan adalah mendeteksi adanya tear pada retina, dan menatalaksana tear tersebut, sebelum berkembang menjadi retinal detachment. ${ }^{1}$

Posterior vitreous detachment (PVD) merupakan sebuah kondisi age-related yang terjadi pada suatu waktu dalam hidup seseorang. PVD dapat menyebabkan traksi pada retina yang menimbulkan terjadinya full thickness retinal breaks (tears dan holes). Resiko lebih tinggi pada inclomplete PVD. Periode paling rentan untuk terjadinya tear setelah PVD akut adalah pada 2 sampai 6 minggu pertama.

Gejala yang sering dikeluhkan adalah adanya flashing dan floaters, dimana sering juga diikuti dengan adanya perdarahan vitreus. Dinyatakan bahwa 33 - $46 \%$ tear retina yang tidak dilakukan tindakan dapat berlanjut menjadi komplikasi retinal detachment, sebuah komplikasi yang membutuhkan intervensi tindakan bedah dan dapat menyebabkan terjadinya kehilangan penglihatan yang irreversibel. ${ }^{1,10}$

Tear retina pada dasarnya terbentuk di area degeratif pada retina periferal. Lesi degeratif pada retina periferal tersebut terjadi pada usia dewasa muda dan meningkat sering dengan bertambahnya usia. Pada beberapa kasus, lesi degenratif ini beresiko menjadi tear retina dan retinal detachment. Bila demikian, kondisi tersebut memerlukan tindakan profilaksis yaitu dengan tindakan laser fotokoagulasi. ${ }^{1,3}$

Fakta bahwa terapi fotokoagulasi dapat meencegah tear retina berlanjut menjadi retinal detachment telah dipubilkasikan sejak 50 tahun yang lalu. Tatalaksana terkini yang direkomendasikan adalah laser retinopexy disekitar (mengelilingi) tear retina. Laser retinopexy dilakukan dengan mengelilingi tear retina dengan barisan tembakan laser yang berdekatan. Pada umumnya, tear dikelilingi sebanyak 2 sampai 3 baris spot laser. ${ }^{1,10}$ 
Pada penelitian ini terdapat 14 subjek dengan tear retina yang dilakukan tindakan laser retinopexy. Kelompok usia terbanyak di rentang 41 - 50 tahun, dengan pembagian jenis kelamin dimana 9 subjek penelitian berjenis kelamin pria $(64,3 \%)$ dan 5 subjek berjenis kelamin wanita $(35,7 \%)$. Pada penelitian yang dilakukan oleh Baser dkk (2014) ${ }^{1}$ juga mendapatkan dari 25 subjek yang diteliti, sebanyak 14 subjek berjenis kelamin pria (56\%) dan 11 subjek berjenis kelamin wanita (44\%), dengan mayoritas kelompok usia di rentang 40 - 66 tahun.

Selain itu, penelitian yang dilakukan oleh Shunmugam dkk (2014) ${ }^{11}$ melaporkan dalam penelitian pasien dengan tear retina, sebanyak 506 subjek penelitian berjenis kelamin pria $(60 \%)$ dan 338 subjek penelitian berjenis kelamin wanita (40\%), dengan rentang usia 50 - 70 tahun. Studi yang dilaksanakan oleh Robertson DM $(1973)^{12}$, menyatakan bahwa distribusi jenis kelamin subjek penelitian sama antara pria dan wanita, dan memiliki rentang usia 50 sampai dengan 70 tahun. Rentang usia pada penelitian ini dan pada beberapa penelitian lainnya ditemukan mayoritas pada usia dewasa muda. Hal ini sesuai dengan teori bahwa resiko terjadinya tear retina berkaitan dengan adanya posterior vitreous detachment (PVD) dan lesi degeneratif pada retina periferal yang timbul pada usia dewasa muda dan meningkat sering dengan bertambahnya usia. Pada beberapa kasus, lesi degeneratif ini beresiko menjadi tear retina akibat traksi yang disebabkan oleh PVD tersebut.

Lateralitas pada penelitian ini mayoritas didapatkan pada mata kiri, sebanyak 10 subjek mata kiri $(71,4 \%)$, dan mata kanan sebanyak 4 subjek penelitian $(28,6 \%)$. Pada penelitian yang dilakukan oleh Robretson DM dkk $(1973)^{12}$ dilaporkan bahwa lateralitas paling banyak ditemukan pada mata kiri yakni sebanyak 159 subjek penelitian dan mata kanan sebanyak 142 subjek penelitian. Hal ini berbeda dengan penelitian Shunmugam dkk $(2014)^{11}$, dimana mayoritas affected eye terjadi pada mata kanan sebesar $55 \%$.

Pada studi deskriptif ini, 13 subjek penelitian memiliki tajam penglihatan yang sama, sebelum dan 2 minggu setelah tindakan laser retinopexy. Pada 13 subjek penelitian tersebut tidak ditemukan komplikasi retinal detachment pada 2 minggu setelah tindakan laser retinopexy. Terdapat 1 subjek penelitian yang mengalami penurunan tajam penglihatan dari $0,5 / 60$ menjadi $1 / 300$, hal ini dikarenakan timbulnya komplikasi retinal detachment pada 2 minggu setelah tindakan laser retinopexy. Pada penelitian ini, dari jumlah total 14 subjek penelitian, ditemukan komplikasi retinal detachment pada 1 subjek penelitian $(7,1 \%)$.

Beberapa penalitian lain juga melaporkan tingkat komplikasi yang rendah. Penelitian yang dilakukan oleh Smiddy WE dkk (1991) 13, melaporkan dari 171 subjek penelitian, didapatkan 15 subjek $(8,8 \%)$ dengan komplikasi retinal detachment setelah tindakan laser fotokoagulasi. Penelitian oleh Pollak A dkk (1981) ${ }^{14}$, menyatakan bahwa terdapat komplikasi retinal detachment setelah tindakan laser fotokoagulasi pada 2 subjek $(2,1 \%)$ dari jumlah total 95 subjek penelitian. Hal ini memperlihatkan bahwa tindakan laser retinopexy pada kasus tear retina cukup baik dalam mengurangi kemungkinan terjadinya komplikasi retinal detachment, walaupun keefektifan tindakan ini masih kontroversial.

Pada penelitian ini didapatkan lokasi tear mayoritas terdapat pada kuadran superotemporal sebanyak 7 subjek penelitian (50\%), kemudian di kuadran inferotemporal sebanyak 6 subjek penelitian $(42,9 \%)$, dan berikutnya di kuadran superonasal sebanyak 1 subjek penelitian $(7,1 \%)$, dan tidak terdapat subjek dengan lokasi tear di kuadran inferonasal. Pada penelitian yang dilakukan oleh Baser G dkk (2014) ${ }^{1}$, dilaporkan hasil yang hampir sama, dimana 
pada penelitian tersebut didapatkan lokasi tear paling banyak ditemukan pada kuadran superior temporal sebanyak 30 subjek penelitian, kemudian kuadran inferior temporal sebanyak 8 subjek penelitian, pada kuadran inferior nasal sebanyak 7 subjek penelitian, dan 6 subjek penelitian memiliki lokasi tear pada kuadran superior nasal.

Studi yang dilaksananakan oleh Shunmugam M dkk (2014) ${ }^{11}$, dilaporkan bahwa lokasi tear mayoritas didapatkan pada kuadran supeotemporal sebanyak 582 subjek penelitian (69 \%), tear pada kuadran superonasal ditemukan sebanyak 341 subjek penelitian (40\%), kemudian pada kuadran inferotemporal ditemukan tear sebanyak 274 subjek penelitian (32\%), dan pada kuadran inferonasal ditemukan tear sebanyak 144 subjek penelitian $(17 \%)$. Dalam penelitian oleh Yoshida I dkk (2018) ${ }^{15}$ juga dinyatakan bahwa lokasi tear paling banyak ditemukan pada kuadran superior temporal (92\%). Hal yang berbeda dikemukakan oleh Straatsma BR $(1980)^{16}$ dalam penelitiannya menyatakan bahwa lokasi tear ditemukan lebih dominan pada kuadran inferior temporal $(58 \%)$. Pada penelitian ini mayoritas ditemukan lokasi tear pada kuadran superior, dengan persentase ditemukannya tear tersebut sebesar $50 \%$.

Hal ini tersebut dipercaya berkaitan dengan teori bahwa posterior vitreous detachment (PVD) memberikan energi tarikan pertama kali (initial force) dari area kuadran superior, dimana pada penelitian ini terbanyak pada kuadran superior temporal. Kemudian disusul dengan lokasi inferotemporal, lalu superonasal, dan terakhir pada kuadran inferonasal. Proporsi tear paling sedikit ditemukan pada kuadran inferonasal, dimana hal ini mendukung teori dimana posterior vitreous detachment (PVD) merupakan sebuah proses yang sekuensial, yaitu sebuah proses yang berkelanjutan dimana setelah intial force terjadi pada kuadran superior, energi tarikan tersebut berlanjut ke area kuadran inferior.
Penelitian deskriptif ini memiliki beberapa kelemahan dan hambatan penelitian, diantaranya yaitu jumlah sampel yang sedikit, subjek penelitian yang tidak dirandomisasi, pemeriksaan tajam penglihatan menggunakan Snellen chart dimana sebaiknya menggunakan logMAR serta waktu follow up yang singkat.

\section{KESIMPULAN DAN SARAN}

Kesimpulan dari penelitian ini mendapatkan jumlah tindakan laser retinopexy pada pasien dengan tear retina di Divisi Vitreoretina, selama periode Januari - Desember 2018 adalah 14 kasus. Pada penelitian ini dibuktikan bahwa dengan menggunakan tindakan laser retinopexy memiliki tingkat keberhasilan yang baik, dimana 13 subjek penelitian $(92,9 \%)$ tidak memiliki komplikasi pasca 2 minggu tindakan laser disertai dengan tajam penglihatan yang menetap, dan 1 subjek ditemukan komplikasi retinal detachment $(7,1 \%)$ disertai dengan penurunan tajam penglihatan. Subjek mayoritas berjenis kelamin pria $(64,3 \%)$ dengan rentang usia terbanyak pada 41 - 50 tahun. Lokasi tear retina terbanyak ditemukan pada kuadran superotemporal (50 $\%)$, kemudian kuadran inferotemporal $(42,9$ $\%)$, kuadran superonasal $(7,1 \%)$, dan kuadran inferonasal $(0 \%)$.

Saran dari penelitian ini, sebaiknya pencatatan data rekam medis yang detail meliputi anamnesa mengenai onset, gejala klinis , detail retina sebelum dan sesudah tindakan laser retinopexy serta diperlukan penelitian lanjutan dengan metodologi penelitian yang berbeda.

\section{Daftar Pustaka}

[1] Baser G, Uyar M, Topaloglu AS, Un ES et al. Long-term Evaluation of Laser Retinopexy in Retinal Breaks: A Review and the Importance of Lifetime Follow-up. Nigerian Journal of Ophthalmology. Volume 22. Issue 1. 2014 : 30 33.

[2] El Sanhouri AA, Foster RE, Petersen MR, Hutchins RK, Miller DM, Evans TM, et al. Retinal Tears After Vitreous Detachment and 


\section{Heme, Vol I No 2}

July 2019

Vitreous Hemorrhage in Patients on Systemic Anticoagulants. Eye 2011 : 1016 - 1019.

[3] Conart JB, Baron D, Berrod JP. Degenerative Lesions of The Peripheral Retina. Journal $\mathrm{Fr}$ Ophthalmology. 2014: 73-80.

[4] Folk JC, Ma C, Blodi CF, Han DP. Occlusion of Bridging or Avulsed Retinal Vessels by Repeated Photocoagulation. Ophthalmology. 1987: 1610 1613.

[5] Van Overdam KA, Bettink-Remeijer MW, Klaver CC, Mulder PG, et al. Symptoms and findings predictive for the development of new retinal breaks. Arch Ophthalmology. 2005 : $479-484$.

[6] Khan AA, Gupta A, Bennett H. Risk stratifying retinal breaks. Canadian Journal Ophthalmology. $2013: 546-568$

[7] Coffee RE, Westfall AC, Davis GH, Mieler WF, Holz ER. Symptomatic posterior vitreous detachment and the incidence of delayed retinal breaks: Case series and meta-analysis. American Journal Ophthalmology. 2007 : 409 - 413.

[8] Blindbaek S, Grauslund J. Prophylactic treatment of retinal breaks-A systematic review. Acta Ophthalmologica. $2014: 1-6$.

[9] Wilkinson CP. Interventions for asymptomatic retinal breaks and lattice degeneration for preventing retinal detachment. $2012: 1-13$.

[10] Moisseiev E, Loewenstein A. Simulation of Laser Retinopexy around Retinal Breaks for Ophthalmologists in Training. New Technologies in Ophthalmology. Ophthalmologica. 2015 : 51 -55 .

[11] Shunmugam M, Shah AN, Hysi PG, Williamson TH. The Pattern and Distribution of Retinal Breaks in Eyes With Rhegmatogenous Retinal Detachment. American Journal of Ophthalmology. Elsevier Inc. 2014 : 221 - 226.

[12] Robertson DM, Norton EW. Long-Term FollowUp of Treated Retinal Breaks. American Journal Of Ophthalmology. $1973: 395$ - 403.

[13] Smiddy WE, Flynn HW Jr, Nicholson DH, Clarkson JG, et al. Results and complications in treated retinal breaks. American Journal of Ophthalmology. 1991: 623-631.

[14] Pollak A, Oliver M. Argon laser photocoagulation of symptomatic flap tears and retinal breaks of fellow eyes. British Journal of Ophthalmology 1981: 469 - 472.

[15] Yoshida I, Shiba т, Hori y, Maeno т. . Relationships between retinal break locations and the shapes of the detachments. Clinical Ophthalmology. 2018 : $2213-2222$.

[16] Straatsma BR. Peripheral Retinal Tears : Classification, Prevalence and Principles of Management. Australian Journal of Ophthalmology. $1980: 275$ - 279.

Email : heme@unbrah.ac.id 